\title{
FOREIGN ENTRY, CULTURAL BARRIERS, AND LEARNING
}

\author{
HARRY G. BARKEMA and JOHN H. J. BELL \\ Department of Economics, Tilburg University, Tilburg, The Netherlands \\ JOHANNES $M$. PENNINGS \\ The Wharton School, University of Pennsylvania, Philadolphia, Pennsylvania, U.S.A.
}

\begin{abstract}
This paper examines the longevity of foreign entries. Hypotheses are developed on the mode (start-ups vs. acquisitions) and ownership structure (wholly owned vs. joint ventures) in relation to cultural distance. The hypotheses are tested within a framework of organizational leaming, using data on 225 entries that 13 Dutch firms carried out from 1966 onwards. Results show that the presence of cultural barriers punctuates an organization's learning. Cultural distance is a prominent factor in foreign cntry whenever this involves another firm, requiring the firm to engage in 'double layered acculuration.' We also identify locational 'paths of learning.' The longevity of acquisitions is positively influenced by prior entries of the firm in the same country. Similarly, the longevity of foreign entries, in which the firm has a majority stake, improves whenever the expanding firm engaged in prior entries in the same country and in other coumtries in the same cultural block.
\end{abstract}

During the last decades firms have increasingly committed themselves to global markets. Globalization confers access to foreign markets, cheap labor, and other advantages. Yet, foreign entry does not come without costs. When firms diversify beyond their national borders, they have to adjust to a foreign national culture. Whenever firms draw other organizations into 'the walk to the unknown' (Johanson and Vahlne, 1977), for example through a joint venture (JV) or an outright acquisition, they have to contend with both a national and a corporate culture. However, over time, firms may learn from previous globalization efforts and reduce the barriers that prevent them from freely tapping cheap labor, new technology, and foreign product markets, and ultimately become veritable multinational enterprises (MNEs).

This study was motivated by the following three research questions. First, what cultural bar-

Key words: international strategy; organizational learning; foreign expansion; cultural differences, entry modes riers exist regarding ventures that differ in magnitude of ownership (wholly owned vs. JV), and mode of ownership (green-field start-up vs. acquisition)? Previous studies have analyzed how cultural barriers influence the incidence or probability of mode and ownership (e.g., Agarwal and Ramaswami, 1992; Gatignon and Anderson, 1988; Kogut and Singh, 1988). In contrast, the present study examines the persistence of different modes and ownership arrangements of foreign ventures, and therefore complements that research on foreign entry (compare Pennings, Barkema, and Douma, 1994).

Second, once firms are established abroad, do they reduce cultural barriers through learning? The literature suggests that MNEs develop the capacity to reduce barriers to foreign entry, for example through a good bargaining position visà-vis host governments (Fagre and Wells, 1982; Lecraw, 1984; Ruygrok and van Tulder, 1993), and through accumulation of foreign experiences, i.e., organizational learning. This paper explores whether firms do indeed reduce the cultural barriers with respect to the performance of various modes and ownership structures of foreign entry, 


\section{through learning from their previous foreign} entries.

Third, can we uncover certain locational patterns of internationalization that endow the firm with more relevant knowledge, in terms of the success of their later ventures, than a 'random strategy' (or no spatial strategy)? Both from a theoretical and a practical point of view, it is desirable that such successful 'paths of learning' be identified. Again, a full disclosure of the issue may hinge on the mode of ownership structure of foreign entries. This paper will present new evidence on all these issues, using panel data on the longevity of foreign expansions.

To date, there is little theoretical or empirical convergence on the antecedents and consequences of foreign direct investment (FDI). Diversity of disciplines among researchers, the theoretical frameworks they adopt, and the national provenance of data they examine yield a disparate body of literature. Much of the research tends to be economic (e.g., Dunning, 1988) while other contributions have a political science orientation (Ruygrok and van Tulder, 1993). Some adopt a static framework while others focus on process. For example, Dunning (1981, 1988), Hennart (1982), Hill, Hwang, and Kim (1990), Hymer $(1960,1976)$ and Teece $(1981)$ generally evaluate a firm's foreign expansions as static choices dictated by relative costs and benefits. In contrast, others focus on internationalization as a process in which firms increasingly move farther from the home country. Examples incude representatives of the Scandinavian School (e.g., Johanson and Vahlne, 1977; Welch and Luostarinen, 1988), but also U.S. contributions by Vernon (1966). Since our research questions both suggest the entangling of dynamic relations over time through learning from earlier expansions and explore locational paths of learning, our paper is anchored in the process-oriented literature.

\section{BACKGROUND}

Three different dynamic models can be distinguished in the process-oriented literature: the product life cycle model (Vernon, 1966), the innovation-adoption inspired internationalization models (Andersen, 1993; Bilkey and Tesar, 1977; Cavusgil, 1980) and the Uppsala (or Scandinavian) process model (Johanson and
Vahlne, 1977, 1990; Johanson and WiedersheimPaul, 1975; Welch and Luostarinen, 1988). For the present study, the Uppsala contributions are most pertinent.

In the product life cycle model, four stages are distinguished: introduction, growth, maturity, and decline of products. A new product will be sold first in the home country, and afterwards internationally. The internationalization of firms is almost solely determined by production cost considerations. In 1979, Vernon retracted his life cycle model, and in fact argued for decreased differences among countries in factor costs and market conditions. His life cycle theory therefore loses much of its validity.

A second model is based on the behavioral theory of the firm, which holds that firms stay in the vicinity of their past practices and the routines which govern them (Cyert and March, 1963). By analogy to the innovation-adoption process (Rogers, 1983), these models distinguish a number of stages of internationalization, arranged as a sequential, fixed development of the internationalization process (e.g., Andersen, 1993; Bilkey and Tesar, 1977; Cavusgil, 1982). The emphasis in these models is on classifying the development into stages, rather than on explaining how firms move from one stage to another. Contributions describe primarily small and mediumsized firms (Bilkey and Tesar, 1977; Cavusgil, 1982) and their early efforts of exporting, until the firm accepts FDI as a common activity (Andersen, 1993).

A third type of model, the Uppsala stage model, also has its theoretical base in the behavioral theory of the firm (Aharoni, 1966; Cyert and March, 1963). This model emphasizes learning, for example familiarization with other national cultures, as the driving force behind the internationalization process of firms. It also tries to identify paths of locational learning. Therefore, this model stands out in framing the questions of the present study.

The Uppsala stage model stipulates organizational learning (Johanson and Vahlne, 1977), consisting of small steps whereby firms gradually increase their international involvement (Johanson and Vahlne, 197\%; Johanson and WicdersheimPaul, 1975). This model resembles the stages model developed by Root (1987). Most firms experience a large amount of uncertainty when operating internationally. In order to reduce 
uncertainty regarding local habits, preferences, market structure, and ways of approaching customers, the sequential steps are small. Lacking routines for the solution of such problems, managers search in the neighborhood of their past experiences (Johanson and Vahlne, 1977).

The Uppsala model emphasizes two aspects. First, the increased commitment to any country unfolds through four successive stages:

Stage 1: no regular export activities;

Stage 2: export via independent agents;

Stage 3: creation of an offshore sales subsidiary;

Stage 4: overseas production facilities.

As Root (1987) has indicated, licenses and joint ventures are also significant as initial steps in obtaining a beachhead abroad. Although the Uppsala model predicts a sequential increase of commitments through four successive stages, also called 'the establishment chain' (Johanson and Vahlne, 1977; Johanson and Wiedersheim-Paul, 1975), exceptions may occur, for example when the firm has considerable experience from markets with similar conditions (Johanson and Vahlne, 1990). The growing foreign presence can be attributed to firms accumulating knowledge about country-specific markets, which is called 'experiential knowledge.' This knowledge is a critical resource since the knowledge needed to operate in any country cannot easily be acquired. During early stages a native partner is required-whether an independent sales agent or a joint venture partner. Next, the firm must learn about local conditions in order to reduce dependence on the indigenous organization. The creation of foreign production facilities is predicated on the knowledge that has been accumulated previously. As we are primarily interested in the firm's path of learning across various foreign cultures, our study will therefore build on the internationalization process model, developed in Uppsala.

A second aspect involves the assumption that firms move to distant countries only after having established a presence in more proximate countries. Firms will successively enter countries with increasing psychic distance. Psychic distance is defined in terms of factors preventing or disturbing the flow of information between the firm and target nations, including linguistic, institutional, cultural, and political factors (Benito and
Gripsrud, 1992; Johanson and Wiedersheim-Paul, 1975). Psychic distance is generally related to geographic distance, although exceptions do occur (e.g., U.S.A. vs. Cuba or U.K. vs. Australia). Only one study (Larimo, 1993) explored geographic distance as an expansion barrier. This study found no support for the greater likelihood of JVs over wholly owned subsidiaries (WOSs) when geographic distance is larger. The author argues that cultural distance is comparatively more significant as a foreign expansion barrier. Learning amounts to reducing the psychic distance between home and host country by expanding knowledge of local conditions.

Various studies have tested the two aspects of the internationalization process model. The first aspect, i.e., the four-stage expansion process, was supported by Johanson and Wiedersheim-Paul (1975). These authors examined the foreign expansions of four Swedish firms from the 1860s until the early 1970s. These firms indeed passed through stages suggested by the internationalization process model. Corroborating evidence was found in Luostarinen (1980), Newbould, Buckley, and Thurwell (1978), and Tschoegl (1982). However, in addition to Johanson and Vahlne (1990), various other studies (Hedlund and Kverneland, 1985, 1986; Johanson and Sharma, 1987; Nordström, 1991; Turnbull, 1987) found exceptions to the general rule of increased commitment through the four successive stages of the establishment chain.

The second aspect of the Uppsala school, i.e., expansion first in proximate countries, then further away, also received mixed support. Davidson (1980) studied the effect of experience and country characteristics on FDI location. Firms in the initial stage of foreign expansion exhibit a strong preference for proximate and comparable cultures, while those in later stages showed no such proclivity. His conclusion was not based on any measure of cultural similarity nor did he conduct a statistical test. Other empirical support was found in Davidson (1983), Denis and Depelteau (1985), and Johanson and Wiedersheim-Paul (1975). However, Benito and Gripsrud (1992), using Kogut and Singh's cultural distance measure (1988), found no support for their hypothesis that current levels of FDI in culturally remote countries will increase with previous levels of FDI. Similarly, Engwall and Wallenstål (1988) could not confirm the hypothesis that firms start 
with FDI in countries culturally closer to the home country. Finally, Sullivan and Bauerschmid (1990) found that managers perceived no differences in cultural barriers at different stages of their firms' internationalization.

In view of the mixed evidence, we believe that the Uppsala school benefits from additional quantitative studies, using alternative methodologies. Our study uses a different proxy for foreign venture success, namely longevity. Furthermore, cultural distance is measured in multiple ways, thus reducing the extent to which findings are method-bound. The ensuing evidence adds to the previous body of results on key notions of the Uppsala school: that cultural barriers are relevant in the foreign entry process, and that firms learn about these barriers through time from their earlier expansions. Following the three central questions in this paper, our theory and evidence focus on later stages in the foreign entry process than most previous studies in the Uppsala tradition. We differentiate between magnitude of ownership (WOS vs. JV), and mode of ownership (green-field start-up vs. acquisition). We also explore paths of locational learning for these different modes of ownership structures. The emphasis on learning requires us to adopt a longitudinal research design that permits the untangling of relationships that are inherently dynamic.

\section{HYPOTHESES}

\section{Foreign expansion and cultural distance}

Both practice and theory (Hofstede, 1980) suggest that some cultures are more distant than others. Globalizing firms adjust to foreign cultures and are more likely to fail whenever the acculturation involved is more demanding. Learning is inherently incremental, and the speed with which organizations expand internationally is subject to what Dierickx and Cool (1989) call 'time compression,' i.e., diminishing returns from efforts to speed up the adjustment process. Acculturation becomes even more challenging in the event that foreign entry is implemented with partners. The ability to sort out relationships with strategic partners is also subject to learning because it is the gradual sorting out of partners' behaviors that enters into the expanding firm's repertoire of skills. Hence the term 'double layered accultura- tion' signaling adjustment to both a foreign national and an alien corporate culture. Finally, it has been argied that firms accumulate global experiences which in turn reduce the odds that subsequent ventures are aborted prematurely. These observations culminate in a number of testable hypotheses that require the explicit modeling of time. First, we hypothesize:

Hypothesis 1: The longevity of foreign ventures is negatively related to the cultural distance between the home and host country.

Firms entering through WOSs or through JVs may both face cultural barriers, but the barriers need not be the same. WOSs require the expanding firm to calibrate itself to a foreign national culture. When firms engage in JVs, this calibration involves 'double layered acculturation.' This dual adjustment applies to majority, $50 / 50$, and minority JVs, although the magnitude of the adjustments need not necessarily be similar among these types of strategic alliances. The implication for the present study is that, compared with WOSs, the termination of JVs is more susceptible to cultural distance. An analogous argument can be made with respect to acquisitions and start-ups. A firm engaged in foreign acquisitions has to accommodate both the target firm's national and corporate cultures. If the target firm resides in a distant culture, divestment is more likely to occur. This leads to the following hypothesis:

Hypothesis 2: The longevity of foreign ventures is more strongly and negatively related to cultural distance in the case of double layered acculturation (JVs and acquisitions), than in the case of single layered acculturation (WOSs and start-ups).

\section{Foreign expansion and learning}

If foreign entry involves a JV or an acquisition, at least two (different) corporate cultures must be integrated to ensure success (Buckley and Casson, 1988; Bueno and Bowditsch, 1989). Whenever a JV is set up with a foreign firm or a foreign firm is acquired in a foreign country, both national and corporate cultures have their impact on the venture, because these are (to some extent) transmitted via institutionalized organizational prac- 
Table 1. Summary statistics on 225 foreign ventures of 13 nonfinancial Dutch firms between 1966 and 1988

\begin{tabular}{|c|c|c|c|c|c|c|c|c|}
\hline Firm & $\begin{array}{l}\text { Sales }^{\mathrm{a}} \\
(1988)\end{array}$ & $\begin{array}{l}\text { Market } \\
\text { value }^{\mathrm{a}} \\
(1988)\end{array}$ & $\begin{array}{c}\text { Expansion } \\
\text { projects }\end{array}$ & $\begin{array}{l}\text { Start- } \\
\text { ups }^{\text {b }}\end{array}$ & WOSs $^{b}$ & $\begin{array}{c}\text { Majorityb } \\
\text { ownership }\end{array}$ & $\begin{array}{l}\text { Minority } \\
\text { ownership }\end{array}$ & Censored $^{c}$ \\
\hline Ahold & 14,638 & 2,770 & 3 & 33.3 & 100.0 & 0.0 & 0.0 & 66.7 \\
\hline DSM & 10,121 & 4,620 & 14 & 50.0 & 78.6 & 0.0 & 14.3 & 92.9 \\
\hline Hoogovens & 7,868 & 2,239 & 20 & 30.0 & 20.0 & 25.0 & 35.0 & 30.0 \\
\hline Heineken & 6,104 & 4,390 & 18 & 27.8 & 44.4 & 38.9 & 16.7 & 88.9 \\
\hline Buhrmann-T & 4,569 & 2,101 & 25 & 36.0 & 68.0 & 16.0 & 8.0 & 40.0 \\
\hline Wessanen & 3,806 & 1,479 & 6 & 66.7 & 83.3 & 0.0 & 0.0 & 66.7 \\
\hline KBB & 3,025 & 809 & 2 & 50.0 & 50.0 & 0.0 & 50.0 & 0.0 \\
\hline HBG & 3,020 & 610 & 3 & 0.0 & 100.0 & 0.0 & 0.0 & 33.3 \\
\hline Hunter Douglas & 2,783 & 1,841 & 31 & 77.4 & 74.2 & 9.7 & 3.2 & 38.7 \\
\hline Internatio-Muller & 2,649 & 497 & 16 & 25.0 & 81.3 & 12.5 & 6.3 & 68.8 \\
\hline KNP & 2,510 & 2,278 & 1 & 100.0 & 0.0 & 0.0 & 100.0 & 100.0 \\
\hline VNU & 2,504 & 1,421 & 14 & 21.4 & 85.7 & 7.1 & 7.1 & 21.4 \\
\hline VOC & 2,410 & 666 & 72 & 61.1 & 65.3 & 9.7 & 13.9 & 50.0 \\
\hline
\end{tabular}

In millions of Dutch guilders (in 1988, the U.S. dollar-Dutch guilder exchange rate was approximately $\$ 0.51$ ).

bFigures are expressed as percentages. The difference between the reported percentages and $100 \%$ indicates the frequency of the omitted category, e.g., of acquisitions in the column for start-ups.

'This column contains the percentage of ventures of the firm initiated during the window that were censored, i.e., still in existence in 1988.

a marked increase around 1966, starting almost from scratch and staying at relatively high levels until the end of the period. For three firmsDAF, KLM and Nedlloyd-the information in the annual reports showed severe gaps. These three firms were omitted from the data set. A venture was called an acquisition if the expansion entailed the takeover of an existing firm or one of its business units, and a start-up if it was a newly established subsidiary. The expansion was called a WOS if the expansion was 100 percent controlled by the Dutch firm; a majority JV if the Dutch firm owned less than 100 percent and more than 50 percent of the equity; a $50 / 50 \mathrm{JV}$ if both firms had a 50 percent stake; and a minority JV if the Dutch firm owned less than 50 percent. Summary statistics on 225 foreign ventures that the 13 remaining firms mentioned in their annual reports are given in Table 1.

\section{Variables}

\section{Longevity'}

Longevity was defined as the number of years that the venture persisted, as evidenced by the firm's annual reports.' This builds on previous

' The annual reports often contain the total list ventures of the firm at a certain point in time. If a venture was dropped studies using this measure, including Carroll et al. (1993), Carroll and Swaminathan (1991), Chowdhury (1992), Geringer and Hebert (1991), Mitchell, Shaver, and Yeung (1994), and Pennings et al. (1994). Geringer and Hebert studied various objective and subjective measures of WOS and JV performance, finding that longevity provides the best estimate of the success of the venture, as (subjectively) experienced by the manager. Thus, when accounting data are unavailable for separate ventures, as in our study, longevity seems to be appropriate. Using a proxy for success as experienced by the manager is consistent with our theoretical framework emphasizing cognitive aspects such as incremental learning and perceived distance in terms of culture.

from this list, this was considered to be a termination. Usually, this was accompanied by another, explicit reference in the annual report. In the very small number of cases where some doubt remained, we resolved this by checking "het Financicele Dagblad' (the Dutch equivalent of the Wall Street Jountal), or clse by telephoning the firm. If a JV changed into an acquisition, we considered the venture to be terminated as a JV. This termination was not coded as an acquisition. In theory, it cannot be excluded that the support for Hypothesis 2 regarding JVs is due to coding JVs ending in acquisitions as terminations. Future research can provide insights in JVs as stepping-stones to full ownership. 
Table 2. Means, standard deviations and correlations of the independent variables $(N=225)$

\begin{tabular}{lrrrrrrrrr}
\hline Variable & Mean & S.D. & \multicolumn{1}{c}{ 1 } & 2 & 3 & 4 & 5 & 6 & 7 \\
\hline LEXPERIENCE & 1.96 & 1.14 & & & & & & & \\
LHOSTEXP & 0.25 & 0.48 & 0.40 & & & & & & \\
LHOSTBLOCK & 0.51 & 0.83 & 0.58 & 0.24 & & & & & \\
LNEARBLOCK & 0.90 & 1.00 & 0.63 & 0.31 & 0.37 & & & & \\
LASSETS & 13.06 & 1.23 & -0.02 & 0.10 & -0.26 & -0.06 & & & \\
ROE & 0.09 & 0.07 & -0.06 & -0.10 & 0.10 & -0.13 & -0.36 & & \\
KSINDEX & 2.64 & 1.14 & 0.18 & -0.02 & 0.33 & 0.32 & -0.27 & 0.17 & \\
RSINDEX & 4.23 & 1.77 & 0.13 & 0.05 & 0.12 & 0.59 & -0.26 & 0.15 & 0.46 \\
\hline
\end{tabular}

If the absolute value of the correlation is greater than 0.110 , the correlation is significant at the 0.05 level.

\section{Foreign experience}

The level of foreign experience was operationalized by LEXPERIENCE, the $\log$ of all foreign expansions that the firm had undertaken, as available in the data set from 1966 onwards. Using the log of the number of previous ventures reflects the assumption that firms learn from their previous experiences at a decreasing rate. Furthermore, LHOSTEXP is the log of the number of previous expansions of the firm in the same host country. For summary statistics regarding this variable, and other independent variables in our analysis, see Table 2.

\section{Cultural blocks}

We also coded cultural blocks of countries, based on clusters identified by Ronen and Shenkar (1985). Gatignon and Anderson (1988) also used this clustering in their empirical study. Ronen and Shenkar (1985) distinguished eight clusters of culturally similar or comparable countries. Some countries, like Brazil and Japan, were not allotted to clusters by Ronen and Shenkar. Based on Hofstede $(1980,1991)$, we placed these countries in the nearest cluster, unless no cultural block was close (as in the case of Japan). ${ }^{2}$ In that case, the country was defined as a separate cultural block.

Based on these clusters, the following blockspecific indices could be constructed as proxies of locational learning in the host country's block,

${ }^{2}$ A few countries in our data set were not included in Hofstede $(1980,1991)$. These countries were allotted to the closest cultural block, after personal communication with Hofstede. and in blocks more proximate than that of the host country, respectively. LHOSTBLOCK is the log of the number of previous expansions of the firm in other countries in the same cultural block as the host country; and LNEARBLOCK is the $\log$ of the number of previous expansions of the firm in cultural blocks that, according to Ronen and Shenkar (1985), were closer to the Nordic block than the cultural block to which the host country belongs.

\section{Cultural distance}

One measure for the cultural distance between the host country and the home country (i.e., the Netherlands) used in this study was the Kogut and Singh index (Kogut and Singh, 1988). This index is used quite often in studies of foreign entry (see, for example, Agarwal and Ramaswami, 1992; Benito and Gripsrud, 1992; Cho and Padmanabhan, 1992). The index is based on the four cultural dimensions in Hofstede's (1980) large-scale study. Scores on the four dimensions for the countries in our study were obtained from Hofstede $(1980,1991) .^{3}$ The measure is called KSINDEX in our study.

We also used a second measure for cultural distance, based on Ronen and Shenkar's (1985) classification, which we called RSINDEX. This measure has a lower score if the cultural block to which the lost country belonged was closer to the Netherlands (ranging from 1, when the host country belonged to the Nordic block, to 8 ,

\footnotetext{
${ }^{3}$ For some countries in our data set, these scores were not available from Hofstede's study. These scores were determined in personal communication with Hofstede.
} 
in the case of Africa). While cruder than the Kogut and Singh index, this measure does not implicitly assume that the four factors identified in Hofstede (1980) are the 'true and only' factors capturing national culture, nor does it assume linearity, additivity, and normal distributions of the scores on these factors.

An imperfection of using the RSINDEX is that it implies treating an ordinal variable as an interval variable. This is not uncommon in strategic management studies, but we will nevertheless also use a second measure based on Ronen and Shenkar (1985), where the eight cultural blocks are used to form seven block dummies, omitting one extreme block dummy (e.g., Nordic) to serve as a benchmark in the analysis. Using this RS dummy measure avoids treating an ordinal variable as an interval variable. Also, the dummy measure does not implicitly assume that the persistence of ventures is linear in the cultural distance to the Netherlands (as the KSINDEX and RSINDEX do). Finally, using the dummy measure provides complementary empirical information, on the significance of differences between the persistence of ventures in the benchmark cultural block on the one hand, and in other cultural blocks on the other hand.

It remains to be seen whether our empirical analysis will be robust for using any of the three measures (the KSINDEX, the RSINDEX, or the RS dummy measure), especially since most earlier studies using Kogut and Singh's measure found insignificant results.

\section{Control variables}

We used two time-variant control variables. LASSETS, the $\log$ of the assets of the firm in the year that the venture was initiated, was used as a proxy for firm size. This variable was included since various studies (Gomes-Casseres, 1985; Larimo, 1993; Stopford and Wells, 1972) found that firm size correlates with the mode of ownership structure of foreign ventures. In addition, firm size may correlate with 'longevity,' since larger firms have more resources in terms of managers, financial resources, and so on, which may enhance the longevity of ventures. Thus, omitting 'firm size' from empirical models might lead to biased estimation results. The variable, Return on Equity (ROE), of the firm in the year that the venture was initiated, was used as a proxy for firm profitability. ROE was included since, as Jensen (1986) argued, more profitable firms are more likely to divert free cash flows to unprofitable expansions, and less inclined to terminate such expansions, which may influence the longevity of ventures. In some analyses we also control for firm-specific (and industry-specific) differences by including dummy variables for each organization in the study.

\section{Analysis}

The analysis was carried out with LIFEREG, an event history analysis method (SAS, 1988). The model used assumes an accelerated failure time or Weibull distribution. This method is suitable for dealing with differences in entry dates, i.e., the shorter period available for relatively late entries before the end of the study period-it controls observations that have not exited by the end of the study. We explored whether the hazard rate of ventures (the converse of the survival rate) covaries with the cultural distance between the host country of the ventures and their home country (the Netherlands), the amount of foreign experience of the firm as proxied by the number of previous foreign ventures of the firm, and so on. Thus, a negative coefficient associated with LEXPERIENCE implies that the probability of venture dissolution declines with the firm's foreign entry experience. More formally, the model can be stated as follows:

$$
\log (h)=a+\sum_{i=1}^{n} b_{i} x_{i}+\operatorname{cog} t
$$

where $\log (h)$ is the logarithmic transformation of the hazard function, and $a, b_{i}$ and $c$ are parameters to be estimated. The $a$ term represents the intercept, the $b_{l}$ terms represent the regression coefficients of $n$ covariates, and $c$, also called 'scale,' indicates the extent to which the log of the hazard increases linearly with the log of time and is constrained to be greater than -1 .

\section{RESULTS}

Hypothesis 1 states that the longevity of foreign entry decreases in cultural distance. It was tested by the KSINDEX. and the two RS measures. The 
results are presented in Table 3 . Columns I and Il show that both the KSINDEX and the RSINDEX have the expected effect and are significant ( $p<0.10$ and $p<0.05$, respectively). Column III presents results based on the RS dummy measure, with 'Nordic' as the omitted category. All dummy coefficients have the expected sign and are significant. Furthermore, visual inspection shows that the order of magnitude of the dummy effects roughly corresponds with their theoretical order, as suggested by Ronen and Shenkar (1985), with Africa being furthest away.

Closer inspection of the data reveals that the results in Column III should be interpreted with some care, since 'Nordic' contains only four ventures. Apparently, these ventures in the same cultural block as the Netherlands persist significantly longer than the ventures in any other block. Another conclusion, however, is that the signifi- cance of all effects associated with the block dummies is driven by the longevity of these four ventures. In itself, it is not exceptional in the strategic management literature to draw conclusions from a small number of observations; for example, the conclusions in Johanson and Wiedersheim-Paul (1975) are based on analyzing four Swedish firms. We nevertheless tested for robustness of the conclusions based on the dummy measure, taking the most remote block 'Africa' (and its 18 ventures) as the benchmark, instead of 'Nordic' (and its four ventures). The results are presented in column IV of Table 3. All seven dummy coefficients in column IV have the expected sign, and three out of four coefficients associated with more proximate blocks (relative to Nordic) are significant, with the fourth (i.e., Anglo) approaching significance $(p=0.11)$. Thus, the support based on the dummy measure

Table 3. Weibull regression results for the hazard of ventures: total sample $(N=225)$

\begin{tabular}{|c|c|c|c|c|c|c|c|}
\hline Independent variables & I & II & III & IV & v & VI & VII \\
\hline Intercept & $\begin{array}{c}1.128 \\
(0.982)\end{array}$ & $\begin{array}{c}0.970 \\
(0.974)\end{array}$ & $\begin{array}{c}-0.252 \\
(1.077)\end{array}$ & $\begin{array}{c}1.843 * \\
(0.960)\end{array}$ & $\begin{array}{l}9.051^{* * *} \\
(2.385)\end{array}$ & $\begin{array}{l}3.071 * * \\
(1.562)\end{array}$ & $\begin{array}{l}7.878^{* * *} \\
(2.563)\end{array}$ \\
\hline KSINDEX & $\begin{array}{c}0.140^{*} \\
(0.079)\end{array}$ & & & & $\begin{array}{c}0.110 \\
(0.073)\end{array}$ & & \\
\hline RSINDEX & & $\begin{array}{c}0.118 * * \\
(0.049)\end{array}$ & & & & $\begin{array}{c}0.076 \\
(0.050)\end{array}$ & \\
\hline Nordic & & & & $\begin{array}{c}-2.095^{* * *} \\
(0.518)\end{array}$ & & & \\
\hline Germanic & & & $\begin{array}{l}1.418^{* * * *} \\
(0.439)\end{array}$ & $\begin{array}{c}-0.677^{*} \\
(0.384)\end{array}$ & & & $\begin{array}{c}0.989 * * \\
(0.443)\end{array}$ \\
\hline Anglo & & & $\begin{array}{l}1.493 * * * \\
(0.433)\end{array}$ & $\begin{array}{c}-0.600 \\
(0.379)\end{array}$ & & & $\begin{array}{l}1.132 * * * \\
(0.431)\end{array}$ \\
\hline Latin Europe & & & $\begin{array}{l}1.386 * * * \\
(0.417)\end{array}$ & $\begin{array}{c}-0.708 * * \\
(0.358)\end{array}$ & & & $\begin{array}{c}0.981^{* *} \\
(0.405)\end{array}$ \\
\hline Latin America & & & $\begin{array}{l}1.658^{* * *} \\
(0.437)\end{array}$ & $\begin{array}{c}-0.437 \\
(0.360)\end{array}$ & & & $\begin{array}{l}1.199 * * * \\
(0.434)\end{array}$ \\
\hline Japan & & & $\begin{array}{l}1.743^{* *} \\
(0.884)\end{array}$ & $\begin{array}{c}-0.351 \\
(0.845)\end{array}$ & & & $\begin{array}{r}1.389^{*} \\
(0.832)\end{array}$ \\
\hline Far East & & & $\begin{array}{l}1.630^{* * *} \\
(0.510)\end{array}$ & $\begin{array}{c}-0.465 \\
(0.466)\end{array}$ & & & $\begin{array}{l}1.366^{* 4 *} \\
(0.493)\end{array}$ \\
\hline Africa & & & $\begin{array}{l}2.095^{* * *} \\
(0.518)\end{array}$ & & & & $\begin{array}{l}1.413^{* * *} \\
(0.512)\end{array}$ \\
\hline ROE & $\begin{array}{c}0.662 \\
(1.197)\end{array}$ & $\begin{array}{c}0.566 \\
(1.190)\end{array}$ & $\begin{array}{c}0.775 \\
(1.170)\end{array}$ & $\begin{array}{c}0.775 \\
(1.170)\end{array}$ & $\begin{array}{c}-0.664 \\
(1.666)\end{array}$ & $\begin{array}{c}-0.651 \\
(1.332)\end{array}$ & $\begin{array}{c}-0.557 \\
(1.199)\end{array}$ \\
\hline Size (log assets) & $\begin{array}{c}0.106 \\
(0.069)\end{array}$ & $\begin{array}{c}0.109 \\
(0.068)\end{array}$ & $\begin{array}{c}0.122^{*} \\
(0.073)\end{array}$ & $\begin{array}{c}0.122 * \\
(0.073)\end{array}$ & $\begin{array}{c}-0.436^{* *} \\
(0.176)\end{array}$ & $\begin{array}{c}-0.037 \\
(0.120)\end{array}$ & $\begin{array}{l}-0.412^{* *} \\
(0.181)\end{array}$ \\
\hline Scale & $\begin{array}{c}0.808 \\
(0.067)\end{array}$ & $\begin{array}{c}0.805 \\
(0.067)\end{array}$ & $\begin{array}{c}0.782 \\
(0.066)\end{array}$ & $\begin{array}{c}0.782 \\
(0.066)\end{array}$ & $\begin{array}{c}0.712 \\
(0.061)\end{array}$ & $\begin{array}{c}0.758 \\
(0.064)\end{array}$ & $\begin{array}{c}0.698 \\
(0.060)\end{array}$ \\
\hline Log likelihood & -244.634 & -243.275 & -239.394 & -239.394 & -221.579 & -227.866 & -218.465 \\
\hline
\end{tabular}

${ }^{*} p \leq 0.10 ;{ }^{* *} p \leq 0.05 ;{ }^{* * *} p \leq 0.01$

Values in parentheses are standard errors.

Coefficients of firm dummies are not shown. 
remains if 18 ventures in the block furthest away (Africa) rather than the four ventures in Nordic are used as a longevity benchmark.

We also tested whether the conclusions are robust for controlling for firm-specific influences, using 12 firm dummies. The results are presented in columns V-VII. For brevity, the coefficients associated with the firm dummies themselves are omitted in the table. The results in columns VVII show that both the KSINDEX effect and the RSINDEX effect approach significance (at the 0.13 and 0.12 level, respectively), while the block dummy effects remain positive and significant. Thus, the support for $\mathrm{Hl}$ weakens somewhat but does not disappear if firm dummies are included in the analysis.

$\mathrm{H} 2$ predicts that longevity decreases more strongly in the cases of double layered acculturation (JVs, acquisitions) than in the cases of single layered acculturation (WOSs, start-ups). We replicated the above testing for these subsets of ventures. The estimation results regarding the RS dummy measure were based on Africa as the omitted category, since findings based on partitioning the four Nordic ventures over two subsets would have made the analysis even more tenuous. The main results from the subsets of JVs $(n=78)$ and WOSs $(n=147)$ were as follows. ${ }^{4}$ For both JVs and WOSs, the KSINDEX effect had the expected positive sign, but was insignificant. Both RSINDEX effects had the expected positive sign, but only in the case of JVs was a significant effect measured $(p<0.05)$. All block dummy effects had the expected sign. There were no JVs in the Nordic block and no WOSs in Japan, hence no comparisons could be made between block dummy effects in these blocks. Three of the remaining dummy effects were significant, all in the case of JVs. These were the effects associated with blocks that in theory were closest to the home country of the expanding firms (Germanic, Anglo, Latin Europe). The combined results are consistent with $\mathrm{H} 2$, that longevity decreases more strongly in the case of JVs than in the case of WOSs.

Since there is no a priori reason to believe that cultural barriers are identical for different types of JVs (see Pennings et al., 1994), we replicated the testing separately for majority JVs:

4 For brevity, we only discuss the main results. The full tables are available from the authors upon request. $(n=29), 50 / 50 \mathrm{JVs}(n=20)$, and minority JVs $(n=29)$. In all three cases, the KSINDEX effect had the expected positive sign but was insignifcant. All three RSINDEX effects had the expected positive sign, with significant effects in the cases of majority JVs and 50/50 JVs $(p<0.05$ and $p<0.10$, respectively). For majority JVs, the three dummy effects associated with blocks that were theoretically close to the expanding country (Germanic, Anglo, Latin Europe) were significant. In the case of 50/50 JVs, only the 'closest' effect (Germanic) was significant. ${ }^{5}$ No significant effects were found in the case of minority JVs. In fact, this was the only subset in our paper for which we obtained some block dummy effects with the 'wrong' sign. In sum, cultural barriers seem most prominent in the cases of majority and 50/50 JVs. No barriers were observed in the case of minority JVs.

As a further test of $\mathrm{H} 2$, the data set was also partitioned into acquisitions $(n=116)$ and startups $(n=109)$. It turned out that both KSINDEX effects had the expected positive sign, but were insignificant. Both RSINDEX effects had the expected positive sign, but only the effect for acquisitions was significant $(p<0.01)$. Three dummy effects associated with acquisitions were significant, with a fourth (Anglo) approaching significance $(p=0.12)$, while two dummy effects were significant for start-ups. These results provide some further support for $\mathrm{H} 2$.

Finally, likelihood ratio tests showed a significant improvement in the results whenever the whole data set was partitioned into more homogeneous data sets (in WOSs and JVs, or in startups and acquisitions). The result from this additional, rather crude test (based on the log likelihood ratios calculated for the respective subsets, correcting for differences in sample size) is consistent with $\mathrm{H} 2$, predicting differential effects of cultural distance on longevity for JVs and WOSs, and for start-ups and acquisitions.

\section{Foreiggn expansion and learning}

Hypothesi: 3 states that foreign expansion experiences have a beneficial effect on the longevity of foreign entry. The relevant estimation results are

SIn fact, there were only $50 / 50 \mathrm{JVs}$ in blocks that were theoretically close, in the Germanic, Anglo and Latin European blocks. 
Table 4. Weibull regression results for the hazard of ventures: total sample, start-ups and acquisitions

Independent

Total sample $(n=225)$

Start-ups $(n=109)$

Acquisitions $(n=116)$

variables

I If III IV

IV

9.889**

(4.367)

0.024

(2.890)

8.864

(6.685)

(0.138)

0.168

$9.048 * *$

$(0.185)$

(3.915)

$(5.380)$

$-0.256$

V VI

LHOSTEXP

$-0.049$

$(0.163)$

0.493*

(0.186)

LHOSTBLOCK

$-0.003$

$(0.293)$

0.137

(0.108)

(0.146)

$0.154^{*}$

0.137

$(0.091)$

LNEARBLOCK

$(0.091)$
-0.360

$-0.667$

(1.180)

$-0.479$

(0.335)

$-0.590^{* * *}$

$(0.123)$

(0.216)

0.716

(0.062)

0.711

$(0.061)$

$-222.762$

$-221.284$

Log likelihood

${ }^{*} p \leq 0.10 ; * * p \leq 0.05 ; * * * p \leq 0.01$

Values in parentheses are standard errors.

Coefficients of firm dummies are not shown.

presented in the first column of Table 4. Since firms may differ in their capacity to learn, we also included dummy variables, controlling for firm differences, in the empirical models used to test hypotheses on learning (Tables 4 and 5). For brevity, the estination results associated with the firm dummies themselves are omitted in these tables. The results in Table 4 suggest that there are no general learning effects. The results in the second column suggest that there are no separate learning effects associated with previous expansions in the same country, or the same cultural block (but a different country), or from blocks that are closer to the home country of the expanding firm.

Hypothesis 4 states that learning from previous experience is stronger in the cases of double layered acculturation (JVs, acquisitions) than for single layered acculturation (WOSs, start-ups). Columns III-VI show that start-ups do not benefit from any type of prior foreign entry, but acquisitions do. $\mathrm{H} 4$ is strongly supported for learning effects (column VI) associated with prior expansions in the same country (LHOSTEXP) and also (at the 0.10 level) with prior expansions in the same cultural block (LHOSTBLOCK). No learning effect is found regarding earlier acquisitions in blocks closer to the loome country of the expanding firm (sign associated with LNEARBLOCK is opposite from what was expected, significant at the 0.10 level).

Estimation results on JVs and WOSs are presented in Table 5. Since different results may apply for different JV types, the results were obtained separately for majority, 50/50, and minority JVs. The results in Table 5 show no significant learning effects in the case of WOSs. In contrast, strong learning effects are found for majority-owned ventures. Both the general learning effect (LEXPERIENCE), and the three separate effects of learning from the same country, from the same cultural block, and from cultural blocks nearer to the home country, have the expected sign and are highly significant. The general learning effect associated with $50 / 50 \mathrm{JVs}$ is similarly significant, but none of the country-specific or block-specific effects are significant. No learning effects were measured in the case of minority JVs (the sign associated with LHOSTEXP is opposite from what was expected, and significant). Obviously, these results are tenuous given the small number of observations.

Tables 4 and 5 also contain information on the 
Table 5. Weibull regression results for the hazard of ventures: WOSs and JVs

\begin{tabular}{|c|c|c|c|c|c|c|c|c|}
\hline \multirow[b]{2}{*}{ Independent variables } & \multicolumn{2}{|c|}{ WOS $(n=147)$} & \multicolumn{2}{|c|}{ Majority JV $(n=29)$} & \multicolumn{2}{|c|}{$50 / 50 \mathrm{JV}(n=20)$} & \multicolumn{2}{|c|}{ Minority JV $(n=29)$} \\
\hline & I & II & III & IV & $\mathrm{V}$ & VI & VII & VIII \\
\hline Intercept & $\begin{array}{c}0.024 \\
(1.512)\end{array}$ & $\begin{array}{c}-0.132 \\
(1.547)\end{array}$ & $\begin{array}{c}-0.593 \\
(5.607)\end{array}$ & $\begin{array}{l}4.353^{*} \\
(2.514)\end{array}$ & $\begin{array}{c}7.931 \\
(11.073)\end{array}$ & $\begin{array}{r}19.254^{*} \\
(11.484)\end{array}$ & $\begin{array}{l}10.176^{*} \\
(5.611)\end{array}$ & $\begin{array}{c}6.634 \\
(5.573)\end{array}$ \\
\hline LEXPERIENCE & $\begin{array}{c}-0.096 \\
(0.099)\end{array}$ & & $\begin{array}{c}-0.446^{* *} \\
(0.213)\end{array}$ & & $\begin{array}{c}-0.890^{* *} \\
(0.396)\end{array}$ & & $\begin{array}{c}0.195 \\
(0.223)\end{array}$ & \\
\hline LHOSTEXP & & $\begin{array}{c}-0.198 \\
(0.285)\end{array}$ & & $\begin{array}{l}-0.458^{* * *} \\
(0.173)\end{array}$ & & $\begin{array}{c}0.441 \\
(0.855)\end{array}$ & & $\begin{array}{c}0.698^{* *} \\
(0.341)\end{array}$ \\
\hline LHOSTBLOCK & & $\begin{array}{c}-0.096 \\
(0.152)\end{array}$ & & $\begin{array}{l}-0.410^{* * *} \\
(0.153)\end{array}$ & & $\begin{array}{c}-0.773 \\
(0.992)\end{array}$ & & $\begin{array}{c}0.052 \\
(0.417)\end{array}$ \\
\hline LNEARBLOCK & & $\begin{array}{c}0.087 \\
(0.143)\end{array}$ & & $\begin{array}{l}-0.221^{* * *} \\
(0.083)\end{array}$ & & $\begin{array}{c}0.588 \\
(0.630)\end{array}$ & & $\begin{array}{c}-0.195 \\
(0.235)\end{array}$ \\
\hline ROE & $\begin{array}{c}0.06 ! \\
(1.775)\end{array}$ & $\begin{array}{c}0.247 \\
(1.873)\end{array}$ & $\begin{array}{c}0.901 \\
(1.534)\end{array}$ & $\begin{array}{c}-0.808 \\
(1.444)\end{array}$ & $\begin{array}{c}-6.083 \\
(4.780)\end{array}$ & $\begin{array}{c}-0.274 \\
(7.535)\end{array}$ & $\begin{array}{c}3.047 \\
(2.586)\end{array}$ & $\begin{array}{l}5.271^{*} \\
(3.035)\end{array}$ \\
\hline Size (log assets) & $\begin{array}{l}0.253^{* *} \\
(0.118)\end{array}$ & $\begin{array}{c}0.251^{* *} \\
(0.120)\end{array}$ & $\begin{array}{c}0.303 \\
(0.469)\end{array}$ & $\begin{array}{c}-0.095 \\
(0.196)\end{array}$ & $\begin{array}{c}-0.244 \\
(0.826)\end{array}$ & $\begin{array}{c}-1.157 \\
(0.824)\end{array}$ & $\begin{array}{c}-0.600 \\
(0.452)\end{array}$ & $\begin{array}{c}-0.316 \\
(0.439)\end{array}$ \\
\hline Scale & $\begin{array}{c}0.928 \\
(0.104)\end{array}$ & $\begin{array}{c}0.937 \\
(0.104)\end{array}$ & $\begin{array}{c}0.258 \\
(0.058)\end{array}$ & $\begin{array}{c}0.179 \\
(0.040)\end{array}$ & $\begin{array}{c}0.617 \\
(0.159)\end{array}$ & $\begin{array}{c}0.712 \\
(0.188)\end{array}$ & $\begin{array}{c}0.375 \\
(0.077)\end{array}$ & $\begin{array}{c}0.347 \\
(0.072)\end{array}$ \\
\hline Log likelihood & -156.530 & -156.464 & -13.273 & -6.634 & -18.333 & -20.270 & -20.824 & -18.843 \\
\hline
\end{tabular}

${ }^{*} p \leq 0.10 ; * * p \leq 0.05 ; * * * p \leq 0.01$

Values in parentheses are standard errors.

Coefficients of firn dummies are not shown.

relative success of various paths of locational learning, from previous expansions in the same country, in other countries in the same cultural block, and in more proximate blocks. Closer inspection of the significant results, regarding acquisitions and majority JVs, shows that both coefficients associated with learning in the host country are larger than in the case of learning in the same or proximate blocks. Thus, the strongest learning effects appear to be associated with previous experience in the same country. Next in size are the two (significant) effects associated with learning from previous expansions in other countries in the same cultural block. Learning from previous expansions in more proximate blocks appears to be weakest in this respect, with only one of the two coefficients being significant (in the case of majority JVs), and the significant effect being smaller than for the other two paths of locational learning (in the case of majority JVs).

Finally, all the analyses were repeated using other distributions than the Weibull distribution which underpins the above results. These distributions include exponential, gamma, log logistic, and log normal. The results generally support our predictions, although Weibull-based results are among the most supportive of the hypotheses. One characteristic of the Weibull distribution is that extremely large values of the dependent variable may bias the estimated parameters. Therefore, we reestimated the results with all 'extremely large' values (more than 2 standard deviations above the sample mean) removed. The results were very similar to the above reported results. We also ran models with time dummies (capturing three 5-year periods, 1966-70, 197175 , and 1976-80, with the remaining years representing the omitted category) instead of firm dummies. In theory, the increased longevity of ventures of firms towards the end of our window of analysis might be caused by other factors than foreign experience, such as more favorable economic or technological conditions. However, the estimation results were similar to the results reported in the paper.

\section{DISCUSSION}

This paper reported new evidence consistent with various key assumptions of the Scandinavian process model on international expansion: that firms face cultural barriers when expanding inter- 
nationally, that firms learn from their previous experience when gradually expanding into cultural space, and that centrifugal expansion patterns are more successful than a random strategy. The results were obtained from data on 225 foreign entries that 13 Dutch firms initiated from 1966 onwards-a time of significant increases in their international exposure.

The present paper focused on FDI, contrary to most previous contributions to the Scandinavian school, that gravitate towards the earlier stages of international expansion. In fact, the above support for the Scandinavian model is particularly relevant since various writers (Johanson and Vahlne, 1990; Johanson and Wiedersheim-Paul, 1975) have questioned the validity of the model for later steps in the internationalization process, both in terms of expansion stage (FDI), and in terms of historic time, due to decreasing transaction costs in the last decades. Our evidence on FDI from expansions from 1966 onwards nevertheless supports key assumptions of the Scandinavian process model.

We also suggested extensions to the model. Consistent with our theory, we found that the impact of cultural distance varied by mode (startups or acquisitions) and ownership structure (WOS or JV) of the expansion. Barriers were found to be more pronounced when the venture required 'double layered acculturation,' and the firm had to accommodate both strange corporate and national cultures. However, acquisitions and JVs were also the very types of ventures where firms reduced cultural barriers through learning, with the success of later ventures increasing in the amount of previous FDI of the firm.

The paper also presented new results on locational learning. When starting a new venture, firms benefit more from previous experience with expansions in the same country, to a lesser extent from previous expansions in other countries in the same cultural block, and least from earlier expansions in blocks that are more proximate to the home country. The strong learning effect from earlier entries in the same country supports the idea that 'experiential' knowledge (Johanson and Vahlne, 1977; Penrose, 1959) from a country is relevant, and that it enhances the success of later expansions in the same country. The beneficial effect from previous experience in other countries in the same cultural block may be due to learning about common cultural characteristics, or because entry in one country allows the firm to connect to other countries through supranational networks (Johanson and Vahlne, 1990) that more likely connect culturally similar countries than countries that are more dissimilar.

Learning effects were only found in the case of new acquisitions and majority and 50/50 JVs. This suggests that learning from previous FDI largely concerns learning about foreign organizational cultures. No significant learning effects from previous FDI were found in the case of WOSs and start-ups, perhaps because such experience adds insufficiently to earlier experience with foreign national cultures through exporting.

At first sight, our result that JVs are more sensitive to cultural distance than WOSs seems paradoxical, in view of earlier results showing that JV incidence increases in cultural distance (see, for example, Kogut and Singh, 1988). Further calculations based on our sample show a similar increase in $\mathrm{JV}$ incidence, relative to WOSs, in cultural distance. However, these results are not surprising if a dynamic perspective is adopted, where firms pursue long-term goals and invest in learning about foreign countries. The results in this paper are from firms that largely began their FDI around the time of the beginning of the window of analysis. Firms in their early stages of FDI may embark on a strategy of foreign entry through JVs despite the cultural barriers involved, because they expect that the initial costs will be more than offset by future gains from present learning. Whether or not firms are willing to bear such initial costs may also depend on their long-term strategy, for example whether they pursue a global, multidomestic, or a transnational strategy.

In fact, we are only on the brink of a fully developed process model explaining how the incidence of various modes and ownership structures of individual ventures varies with cultural distance, how the costs and benefits (e.g., learning benefits) of ventures vary with cultural distance, and how the willingness to bear such costs is linked to the strategy of the firm. Future studies may provide more insight here.

\section{Suggestions for further research}

We end this paper with some suggestions for further research. Our results on the longevity of ventures complement previous work on the 


\section{incidence of various modes (start-ups or} acquisitions) and ownership structures (WOSs vs. JVs) as a function of cultural distance (Agarwal and Ramaswami, 1992; Benito and Gripsrud, 1992; Gatignon and Anderson, 1988; Hennart, 1991; Kogut and Singh, 1988). In general, duration of foreign entry is presumed to be a sound indicator of success. Geringer and Hebert (1991) argue that both survey and archival or 'objective' proxies of success should be used. Absent the former, longevity as a success measure is justifiable. Mitchell et al. (1994) reviewed many studies documenting a positive relationship between longevity and financial performance. However, longevity is not a perfect measure of performance. Dissolution may not always imply failure, and longevity does not always signal success. Performance is a multidimensional phenomenon that covers financial returns, risk reduction, knowledge transfer, and so on. Future studies on globalizing firms could add to the present study by using other success measures.

This study used three measures of cultural distance: the Kogut and Singh measure, and two measures building on Ronen and Shenkar's (1985) concept of cultural blocks. This adds to previous qualitative studies supporting the Scandinavian process model (e.g., Johanson and Wiedersheim-Paul, 1975), and to quantitative studies using the Kogut and Singh measure that fail to find such support (e.g., Benito and Gripsrud, 1992). This lack of support suggests that the hypothesis subjected to test might be untrue. It might also be incorrect to assume that the four factors in Hofstede (1980) are the 'true and only' factors capturing cultural distance and the assumptions regarding the linearity, additivity, and normal distributions of scores, etc. While cruder than the Kogut and Singh measure, the measures building on Ronen and Shenkar (1985) use the common wisdom of eight previous empirical studies (including Hofstede's original 1980 study). Future studies may consider the validity and reliability of the various measures and possibly develop alternative measures. Eventually, this may lead to conclusions about the effects of cultural distance on the incidence of success of various modes of ownership structures of foreign ventures that are robust for changes in method assumptions.

Future quantitative studies could also investigate whether our conclusions are robust for using data on expanding firms from other home countries and/or different cultural blocks. In theory, this could very well lead to different conclusions. For example, numerous anecdotes in the popular press suggest that Japanese firms adjust more rapidly to local conditions in the U.S.A. than vice versa. Before entry takes place, Japanese firms may be better informed about the U.S. culture than vice versa, due to an asymmetric information exposure about their respective cultures, through printed and electronic media (e.g., U.S. textbooks used in Japan rather than vice versa), newspapers (U.S. newspapers like Business Week, Fortune, and so on are widely read in Japan, while Americans are somewhat oblivious to Japanese press coverage), and TV. Even after entry, learning effects may be asymmetric. Studies by Brown et al. (1989) and Reich and Mankin (1986) argue that in JVs Japanese managers focus more on learning and less on information sharing than their U.S. counterparts. This story is just one illustration that evidence on the magnitude of cultural barriers and on learning effects may be sensitive to the particular home country of the expanding firm. Future studies may provide more insight here.

A last suggestion is to examine learning effects in the most advanced stages of internationalization, i.e., after globalization has become fully institutionalized. At this stage, the role of cultural barriers and learning may become less prominent. Future studies, including in-depth studies of foreign expansions, may provide more insights in this respect.

\section{CONCLUSION}

Firms are increasingly entering global markets, seeking cost advantages through lower labor costs in foreign countries, and following the demand for their products. The results in this study showed that firms entering the global game of FDI face cultural adjustment costs, especially when they engage in double layered acculturation, such as in the case of acquisitions and majority and 50/50 JVs. However, the results also showed that expanding firms can move along a learning curve in such ventures, especially when they choose their expansion path such that they can exploit previous experience in the same country, and in other countries in the same cultural block. 
stages'. In M. R. Czinkola and G. Tesar (eds.),

Export Management: An International Context. Praeger, New York, pp. 276-286.

We acknowledge the research assistance of Jolanda van Werkhooven and Erwin Fransen, and cross-national methodology advice from Geert Hofstede and Oded Shenkar. We also appreciate the comments of Paul Allison, Jay Anand, Bruce Kogut, Alain Verbeke, two anonymous reviewers and members of the Jones Center Seminar at the Wharton School, although any errors remain our responsibility.

\section{REFERENCES}

Agarwal, S. and S. N. Ramaswami (1992). 'Choice of organizational form in foreign markets: A fransaction cost perspective', Paper presented at the 1992 AIB Annual Meeting, Brussels.

Aharoni, Y. (1966). The Foreign Investment Decision Process. Harvard Business School, Boston, MA.

Andersen, O. (1993). 'On the internationalization process of firms: A critical analysis', Journal of International Business Studies, 24(2), pp. 209-231.

Benito, G. R. G. and G. Gripsrud (1992). 'The expansion of foreign direct investments: Discrete rational location choices or a cultural learning process?', Journal of International Business Studies, 23(3), pp. 461-476.

Bilkey, W. J. and G. Tesar (1977). 'The export behavior of smaller Wisconsin manufacturing firms', Journal of International Business Studies, 8, pp. 93-98.

Brown, L. T., A. M. Rugman and A. Verbeke (1989). 'Japanese joint ventures with western multinationals: Synthesizing the economic and cultural explanations of failure', Asia Pacific Journal of Management, 6(2), pp. 225-242.

Buckley, P. J. and M. Casson (1988). 'A theory of cooperation in international business'. In F. J. Contractor and P. Lorange (eds.), Cooperative Strategies in International Business. Lexington Books, Lexington, MA, pp. 31-55.

Bueno, A. and J. Bowditsch (1989). The Human Side of Mergers and Acquisitions. Managing Collisions between People, Cultures, and Organizations. Jossey-Bass, San Francisco, CA.

Carroll, G. R., P. Preisendorfer, A. Swaminathan and G. Wiedenmayer (1993). 'Brewery and brauerei: The organizational ccology of brewing', Organization Studies, 14(2), pp. 155-188.

Carroll, G. R. and A. Swaminathan (1991). 'Density dependent organizational evolution in the American brewing industry from 1633 to 1988', Acta Sociologica, 34(3), pp. 155-175.

Cavusgil, S. T. (1980). 'On the internationalization process of firms', European Research, 8, pp. 273281.

Cavusgil, S. T. (1982). 'Some observations on the relevance of critical variables for intemationalization
Cho, K. R. and P. Padmanabhan (1992). 'Acquisition versus new venture: The choice of foreign establishment mode', Paper presented at the 1992 AIB Annual Meeting, Brussels.

Chowdhury, J. (1992). 'Performance of international joint ventures and wholly owned foreign subsidiaries: A comparative perspective', Management International Review, 32(2), pp. 115-133.

Cyert, R. M. and J. G. March (1963). A Behavioral Theory of the Firm. Prentice-Hall, Englewood Cliffs, NJ.

Davidson, W. H. (1980). 'The location of foreign investment activity: Country characteristics and experience effects', Journal of International Business Studies, 11, pp. 9-22.

Davidson, W. H. (1983). 'Market similarity and market selection: Implications of international marketing strategy', Journal of Business Research, 11, pp. 439-456.

Denis, J. E. and D. Depelteau (1985). 'Market knowledge, diversification and export expansion', Journal of International Business Studies, 16, pp. 77-89.

Dierickx, I. and K. Cool (1989). 'Asset stock accumu-' lation and sustainability of competitive advantage', Management Science, 35(12), pp. 1504-1514.

Dunning, J. H. (1981), International Production and the Multinational Enterprise. Allen \& Unwin, London.

Dunning, J, H. (1988). Explaining Internationa' Production. Unwin Hyman, London.

Engwall, L. and M. Wallenstål (1988). 'Tit for tat in small steps: The internationalization of Swedish banks', Scandinavian Journal of Management, 4,(3/4), pp. 147-155.

Fagre, N. and L. T. Wells, Jr. (1982). 'Bargaining power of multinationals and host governments', Journal of International Business Studies, 13(2), pp. 9-23.

Gatignon, H. and E. Anderson (1988). 'The nultinational corporation's degree of control over foreign subsidiaries: An empirical test of a transaction cost explanation', Journal of Law, Economics, and Organization, 4(2), pp. 305-336.

Geringer, J. M. and L. Hebert (1991). 'Measuring performance of international joint ventures', Journal of International Business Studies, 22(2), pp. 249263.

Gomes-Casseres, B. (1985). Multinational Ownership Strategies. University of Michigan Press, Ann Arbor, MI.

Hedlund, G. and A. Kverneland (1985). 'Are strategies for foreign markets changing? The case of Swedish investment in Japan', Intermational Studies of Management and Organization, XV(2), pp. 41-59.

Hedlund, G. and A. Kvemeland (1986). "Why is there so little foreign direct investment in Japan? A review of Swedish companies' experience', Advances in International Management, 1, pp. 47-68.

Hennar, J-F. (1982). A Theory of Multinational Enterprise. University of Michigan Press, Ann Arbor, MI. 
Hennart J-F. (1991). 'The transaction costs theory of joint ventures: An empirical study of Japantese subsidiaries in the United States', Management Science, 34(4), pp. 483-497.

Hill, C. W. L., P. Hwang and W. C. Kim (1990). 'An eclectic theory of the choice of international entry mode', Strategic Management Journal, 11(2), pp. 117-128.

Hofstede, G. (1980). Culure's Consequences: International Differences in Work-related Values. Sage, Beverly Hills, CA.

Hofstede, G. (1991). Cullures and Organizations: Software of the Mind. McGraw-Hill, Berkshire, UK. Hymer, S. H. (1960). 'The international operations of national firms: A study of direct foreign investment', PhD dissertation, Massachusetts Institute of Technology, Cambridge, MA.

Hymer, S. H. (1976). The International Operations of National Fimm: A Study of Direct Foreign Investment. MIT Press, Cambridge, MA.

Jensen, M. C. (1986). 'Agency costs of free cash flow, corporate finance, and takeovers', American Economic Review, 76, pp. 323-329.

Johanson, J. and D. D. Sharma (1987). 'Technical consultancy in internationalization', International Marketing Review, 4, pp. 20-29.

Johanson, J. and J.-E. Vahlne (1977). 'The internationalization process of the firm: $A$ model of knowledge development and increasing foreign market commitments', Journal of International Business Studies, 8, pp. 23-32.

Johanson, J. and J.-E. Vahlne (1990). 'The mechanism of internationalization', International Marketing Review, 7(4), pp. 11-24.

Johanson, J. and F. Wiedersheim-Paul (1975). 'The internationalization of the firm: Four Swedish cases', Journal of Management Studies, 12(3), pp. 305-322. Kogut, B. and H. Singh (1988). 'The effect of national culture on the choice of entry mode', Journal of International Business Studies, 19(3), pp. 411-432.

Larimo, J. (1993). Foreign Direct Investment Behaviour and Performance: An Analysis of Finnish Direct Manufacturing linvestments in OECD Countries. Acta Wasaensia, no. 32., University of Vaasa, Vaasa, Finland.

Lecraw, D. J. (1984). 'Bargaining power, ownership, and profitability of transnational corporations in developing countries', Journal of International Business Studies, 15(2), pp. 27-43.

Luostarinen, R. (1980). Internationalization of the Fim. Helsinki School of Economics, Helsinki, Finland.

Mitchell, W., J. M. Shaver and B. Yeung (1994). 'Foreign entrant survival and foreign market share: Canadian companies' experience in United States medical sector markets', Strategic Management Journal, 15(7), pp. 555-567.

Newbould, G. D., P. J. Buckley and J. Thurwell (1978). Going International: The Experience of Smaller Companies Overseas. Associated Business Press, London.

Nordström, K. (1991). The Internationalization Process of the Firm: Searching for New Patterns and Explanations. Institute of International Business, Stockholm School of Economics, Stockholm, Sweden.

Pennings, J. M., H. G. Barkema and S. W. Douma (1994). 'Organizational learning and diversification', Academy of Management Journal, 37(3), pp. 608640.

Pennings, J. M. and F. Harianto (1992). 'Technological networking and innovation implementation', Organization Science, 3, pp. 356-382.

Penrose, E. (1959). The Theory of the Growth of the Firm. Basil Blackwell, London.

Reich, R. B. and E. D. Mankin (1986). 'Joint ventures with Japan give away our future', Harvard Business Review, 64, pp. 78-86.

Rogers, E. M. (1983). Diffusion of Imovations (3rd ed.). Free Press, New York.

Ronen, S. and O. Shenkar (1985). 'Clustering countries on attitudinal dimensions: A review and synthesis', Academy of Management Review, 10(3), pp.435454.

Root, F. R. (1987). Entry Strategies for International Markets. Lexington Books, Lexington, MA.

Ruygrok, W. and R. van Tulder (1993). 'The ideology of interdependence', doctoral dissertation, Department of Political Science, University of Amsterdam, Amsterdam, The Netherlands.

SAS (1988). SAS Users Guide: Statistics. SAS Institute, Durham, NC.

Shenkar, O. (1992). 'The national/corporate culture matrix in international joint ventures', Paper presented at the 1992 AIB Annual Meeting, Brussels.

Stopford, J. M. and L. T. Wells, Jr. (1972). Managing the Multinational Enterprise: Organization of the Firm and Ownership of the Subsidiaries. Basic Books, New York.

Sullivan, D. and A. Bauerschmidt (1990). 'Incremental internationalization: A test of Johanson and Vahlne's thesis', Management International Review, 30(1), pp. $19-30$.

Teece, D. J. (1981). 'The multinational enterprise: Market failure and market power considerations', Sloan Management Review, 22, pp. 3-17.

Tschoegl, A. E. (1982). 'Foreign bank entry into Japan and California'. In A. M. Rugman (cd.), New Theories of the Multinational Enterprise. Croom Helm, London, pp. 196-216.

Turnbull, P. W. (1987). 'A challenge to the stages theory of the internationalization process'. In S. D. Reid and P. J. Rosson (eds.), Managing Export Entry and Expansion. Praeger, New York, pp. $2 \hat{\imath}-40$.

Vernon, R. (1966). 'International investment and international trade in the product cycle', Quarterly Journal of Economics, 80, pp. 190-207.

Vernon, R. (1979). 'The product cycle hypothesis in the new international environment', Oxford Bulletin of Economics and Statistics, 41, pp. 255-267.

Welch, L. S. and R. Luostarinen (1988). 'Internationalization: Evolution of a concept', Journal of General Management, 14(2), pp. 34-55. 